This item was submitted to Loughborough's Research Repository by the author.

Items in Figshare are protected by copyright, with all rights reserved, unless otherwise indicated.

\title{
Assessing service delivery systems for assistive technology in Brazil using HEART study quality indicators
}

PLEASE CITE THE PUBLISHED VERSION

http://dx.doi.org/10.3233/TAD-160438

PUBLISHER

IOS Press

VERSION

AM (Accepted Manuscript)

\section{PUBLISHER STATEMENT}

This work is made available according to the conditions of the Creative Commons Attribution-NonCommercialNoDerivatives 4.0 International (CC BY-NC-ND 4.0) licence. Full details of this licence are available at: https://creativecommons.org/licenses/by-nc-nd/4.0/

\section{LICENCE}

CC BY-NC-ND 4.0

\section{REPOSITORY RECORD}

Maximo, Tulio, and Laurence Clift. 2016. "Assessing Service Delivery Systems for Assistive Technology in Brazil Using HEART Study Quality Indicators”. Loughborough University. https://hdl.handle.net/2134/21635. 


\title{
Assessing Service Delivery Systems for Assistive Technology in Brazil using HEART Study quality indicators.
}

\author{
Tulio MAXIMO and Laurence CLIFT \\ Loughborough Design School, Loughborough University, Leicestershire, UK
}

\begin{abstract}
BACKGROUND: recently in Brazil, there has been investment and improvements in the service delivery system for assistive technology provision. However, there is little documentation of this process, or evidence that users are being involved appropriately. OBJECTIVE: to understand how assistive technology service provision currently functions in Belo Horizonte city, Brazil, in order to provide context-specific interventions and recommendations to improve services. METHOD: Qualitative research design, including visits to key institutions and semi-structured interviews with key stakeholders. Interview questions were divided with two purposes: 1) Exploratory, aiming to understand present service functioning; 2) Evaluative, aiming to assess staff difficulties in applying existing best practice. RESULTS: Assistive Technology services in Belo Horizonte fall under the 'medical model' definition of the service delivery system developed by AAATE. It was also found that staff lack training and knowledge support to assess user requirements and to involve them during the decision making process. Additionally, there is no follow-up stage after the device is delivered. CONCLUSIONS: The study clearly defines the service provision function and the staff difficulties at Belo Horizonte city, providing information for further studies.
\end{abstract}

Keywords. Service Delivery System, Assistive Technology, User Influence.

\section{Introduction}

\subsection{Research aims}

This research aims to understand how assistive technology service provision functions in Belo Horizonte city, Brazil, in order to provide context-specific interventions and recommendations to improve the design of current assistive technology services.

The research comprises three main stages: an exploratory stage to understand the systems and identify a research focus; a preparatory stage to set the parameters for an intervention; and a testing stage to test and improve the intervention. This paper describes the exploratory stage.

The results and views here published are totally independent from the sponsors and the institutions taking part. The authors had no association with the institutions involved or sponsoring any research previous to this research. 


\subsection{The definitions of the term assistive technology}

One widely used definition of assistive technology is recommended by the Association for the Advancement of Assistive Technology in Europe (AAATE), which states:

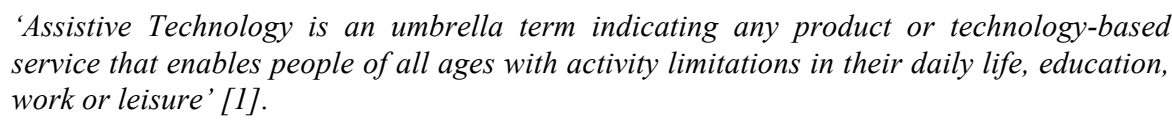

Confusion is often present in with regard to the definition and terms used to refer to assistive technologies in Brazil. Common terms used are ajudas técnicas, tecnologia assistiva and tecnologia de apoio. While the term ajudas técnicas frequently make reference only to devices, the terms tecnologia assistiva and tecnologia de apoio often covers services and methodologies. The term ajudas técnicas is the one used on federal decrees [2,3]. Despite the differences between the terms they are often used as synonyms [4]. For present purposes, devices will be distinguished from services by using the terms assistive technology devices (ATD) to refer to the devices, assistive technology services (AT services) to refer to the services and Service Delivery System (SDS) to refer to the system that provides both ATD and AT services.

\subsection{The Health Care and the Assistive Technology Provision in Brazil}

Health care in Brazil is provided by a complex of system and subsystems of public and private care [5]. Brazil is the only country with a population larger than 100 million inhabitants to declare healthcare as a duty of the State and a civil right [6]. The Brazilian national health service (Serviço Único de Saude - SUS) is the only health service option for over 150 million Brazilians, nearly three-quarters of the Brazilian population [7]. The service started providing assistive technologies devices (ATD) as early as 2002 and, as recently as 2007 , the orthotics and prosthetics department had a demand of 1,042,000 people waiting to receive a device [8]. In the following year, the United Nation Convention on the Rights of Persons with Disabilities (UN CRPD) was ratified in Brazil. Later in 2009, the UN CRPD was published in the federal decree 6.949/2009 giving the convention power of Constitutional Amendment [9].

In order to pave the way for the UN CRPD to function by means of public policies the government created in 2011 the national plan for the rights of disabled people Viver Sem Limites (VSL) with investment estimates around US \$3.52bn for the first four years of the program [10]. VSL articulates policies regarding social inclusion, access to education, accessibility and health care. The VSL policies regarding the health care sector, which was the focus of this study, includes disability identification and early intervention programs, developing therapeutic guidelines, the creation of a net of rehabilitation centres, creation of orthopaedic workshops, creation of odontology centres, and capacitation of professionals working at these different centres [10].

Various resources were made available to promote ATD acquisition, AT services and to the Service Delivery System (SDS) used to provide them. As a consequence, ATD acquisition has boomed in Brazil since the start of the program. For example, 36,722 wheelchairs were delivered in 2011 compared to 19,890 delivered in 2008 [11]. It should be noted, however, that all these improvements are recent and there is a lack of research and data available, apart from government publications, regarding the 
functioning of these services. Also, there is a lack of research and publication investigating whether user requirements and SDS' best practices are being considered and implemented.

Europe has a long tradition in the provision of ATDs and AT services by means of public health services $[1,12,13]$. An example of this tradition is the Horizontal European Activities in Rehabilitation Technology (HEART), a Research and Development programme promoted by the European Commission. The HEART Study was carried out between 1993 and 1995 by a consortium of 21 institutions, organizations and companies in 12 countries, under the leadership of the Swedish Institute of Assistive Technology [13]. The goal was to survey the present situation regarding assistive technology in Europe and to propose actions to encourage cooperation, convergence and exchange. Overall, it produced over 50 reports, books and brochures. The findings and recommendations are still valid for analysing the service delivery systems in place today as well as for discussing roadmaps for improvement $[1,12,13]$.

The research presented in this paper focuses on the ATD and AT services provided by means of the SUS SDS, classifying existing SDS in Belo Horizonte, Brazil, using European theoretical frameworks developed by the Association for the Advancement of Assistive Technology in Europe (AAATE) and the European Assistive Technology Information Network (EASTIN) [1], both institutions being directly involved in the HEART study. These were employed with the HEART study user influence quality indicator to assess the current state of services in Belo Horizonte city, Brazil. The user influence is defined in AAATE and EASTIN [1] as:

\footnotetext{
"A service delivery system takes advantage of the user influence when it empowers, actively involves and makes the user participate in responsibilities in all decisional processes related to assistive technology interventions. The lack of user involvement exposes the process to the risk of wrong or ineffective intervention, abandonment of the devices provided and waste of resources. User influence indicators include the presence and strength of user organisations, the availability of juridical protection of the user's rights, the involvement of users at a policy level, the user empowerment during the individual assessment, communication with the user in the service delivery process and the influence of the user on decisions in the process."
}

It worth mentioning that other models and frameworks rather than AAATE were considered, such as Cook and Hussey's Human Activity Assistive Technology [14] and Gelderblom et al Matching the Person and Technology [15]. The main reason for selecting AAATE model is that it focuses on SDS, providing clear quality indicators for assessing them.

\subsection{Why Belo Horizonte City?}

Brazil is a continent sized country in South America with an estimated population of more than $204 \mathrm{~m}$ inhabitants [16], of which $84 \%$ live in urban areas [17]. The Brazilian healthcare service, SUS, is structured to function similarly across the whole country. The system is integrated into the municipalities, states and union services. Despite great centralization of SUS management in the past, the focus has shifted from union level to a shared responsibility between union, estate and municipality levels [18]. 
Consequently, it has become more important to understand the municipality context in order to investigate its current issues and provide context-specific interventions.

Belo Horizonte is the capital of Minas Gerais state, with an estimated population of 2,502,557 persons [19]. The Belo Horizonte municipalities have the greater concentration of disabled population in Minas Gerais, following the national trend of the disabled population being concentrated in urban areas [20]. A hypothesis that might explain this is the greater infrastructure of education, health and transport available in urban areas [21]. Like the rest of the country, Belo Horizonte represents a heterogeneous, unequal and complex space that needs to be understood [21].

Following the national trend of growing investment in order to overcome the restrained demand, ATD provision in Belo Horizonte has increased from 2,722 devices provided to 2,717 users in 2008 to 3,503 devices provided to 3,299 users in 2012, according to data from Belo Horizonte Municipal Health Office (Secretaria Municipal de Saúde - SMSA)[22].

\section{Methodology}

The following research questions have driven the research design and methods selection for this exploratory stage:

- What are the characteristics of the existing assistive technology services provided by SUS in Belo Horizonte city?

- To what extent does the current assistive technology service provided by SUS in Belo Horizonte city apply user-centred service provision best practice?

Qualitative data were collected by visiting major institutions providing AT services in Belo Horizonte city $(\mathrm{n}=5)$ and conducting semi-structured interviews with the stakeholders directly involved in these services $(n=28)$. Information collected was confirmed in the preparatory stage study, with further interviews $(n=12)$ and participant observation $(n=128)$ during a period of three months at three main public institutions providing AT services in Belo Horizonte city.

In order to have a better understanding of an AT SDS, various authors suggest that different roles and professions must be consulted [1, 23, 24, 25]. Theoretical sampling was used to identify the key participants to be interviewed. Participants to be interviewed were defined from the pilot study $(n=7)$ where the main occupations working with assistive technology at Belo Horizonte' SUS were identified and the interview schedule tested and improved. Participants were healthy individuals, aged 18-65 years, working as occupational therapists, physiotherapists, service administrators, service coordinators, assistive technology suppliers and assistive technology technicians. The population studied was from Belo Horizonte city in Minas Gerais estate, Brazil.

The institutions included in the study were grounded from the literature, which identified the main institutions proving AT public service provision in Belo Horizonte city by means of SUS, which were: 
- Centro Geral de Reabilitação (Municipality accountability).

- CReab Leste (Municipality accountability).

- CReab Norte (Municipality accountability).

- Associação Mineira de Reabilitação (AMR) (Philanthropic accountability).

- Coordenação de rehabilitação (Municipality accountability).

The first three institutions described are the rehabilitation centres providing AT services to the SUS in Belo Horizonte. AMR is a Philanthropic institution providing ATDs and AT services in Belo Horizonte and also a SUS's supplier for ATDs and AT services. Coordenação de Rehabilitação is the public institution which is responsible for coordinating the SUS rehabilitation centres and contracting the AT suppliers, among other duties. To protect the rehabilitation centres identity they are referred in this publication by a given random number.

All interviews were conducted by the same researcher, in Portuguese language and guided by the use of interview schedules. The audio records from the interviews were transcribed using transcription conventions adapted from Josetti [26] and coded using a thematic analysis approach to identify key topics.

Ethical approval was gained from ethical committee departments of Loughborough University, Belo Horizonte Municipal Health Office and Plataforma Brasil (CAAE: 30221114.0.0000.5140), the latter of which is the official means for getting approval to conduct research at SUS. Data collected in the fieldwork were uploaded in the qualitative data analysis software NVivo, version 10.0.

\subsection{Design of Interviews schedule and analyse approach}

Semi-structured interviews were designed to identify issues with the SDS, and to invite interviewees to evaluate their experiences of it. The interview schedule was therefore divided in two parts, which were analysed using different approaches to the thematic analysis. The first part enclosed questions with exploratory purpose and was analysed using an inductive approach, in which identified categories were strongly linked to data [27]. Exploratory questions related to the functioning of the service, type of ATD provided and staff difficulties and opinions towards service improvement. The second part of the interview included evaluative questions and was analysed using a deductive approach, for which categories were defined prior to data collection [27]. Questions were related to the implementation of the HEART Study recommendations [1, 13]. It was found that assessing the entire set of HEART Study's quality indicators would undermine the study's exploratory goal, due to the large amount of information necessary to be collected in order to cover all aspects of the service. For this reason this study focused assessing solely the "user influence" quality indicator.

Two different interview schedules were developed in this study. One interview schedule was developed specific to the service administrative and coordination staff. The other interview schedule was developed specific to the medical staff, AT technician and supplier's staff. Whilst both interview schedules contained both exploratory and evaluative questions, the administrative/coordination staff schedule focused on exploratory questions while the other schedule focused on evaluative questions. 


\section{Findings and Discussion}

\subsection{Service Delivery System Functioning}

The SDS for public provision of ATD and AT services in Brazil occurs by means of rehabilitation centres at the secondary level of care. AT for public provision can be prescribed by occupational therapists, physiotherapists, orthopaedic practitioners, physicians or physiatrists. Referrals are accepted from both private and public medical institutions. Nonetheless, every person should be reassessed at SUS's rehabilitation centres for the identification of an assistive solution, which describes the set of human and technology supports needed by an individual to compensate for disablement and participate in society on equal footing [1]. This assistive solution is limited to a list of devices called the SIA/SUS list, describing the device specifications and established price. The list contains 95 items, adaptations and substitutions to be provided without any cost to the user. (See Table 1).

It is worth mentioning that there are other items of ATDs and AT services guaranteed by law $[2,3]$ not included on this list, such as devices and human support to facilitate education and work. This research focused on the ATDs delivered at the rehabilitation centres by means of the SIA/SUS list.

Table 1. Types of Assistive Technology included on SIA/SUS list.

\begin{tabular}{lclc}
\hline \multicolumn{1}{c}{ Type of Assistive Technology } & Variety & \multicolumn{1}{c}{ Type of Assistive Technology } & Variety \\
\hline Bath Chair & 4 & Prosthetics for the lower limbs & 11 \\
Cane & 1 & Prosthetics for the upper limbs & 12 \\
Crutches & 2 & Prosthetic parts (for the lower limbs) & 4 \\
Inner Sole & 4 & Prosthetic parts (for the upper limbs) & 4 \\
Orthotics used at the cervical region & 2 & Shoes & 5 \\
Orthotics used at the lower limbs & 12 & Walking Frame & 1 \\
Orthotics used at the pelvic and lower limbs & 3 & Wheelchairs & 5 \\
Orthotics used at the pelvic region & 3 & Wheelchair' Adaptations & 8 \\
Orthotics used at the thoracic and back region & 10 & White Stick & 1 \\
Orthotics used at the upper limbs & 3 & & \\
\hline
\end{tabular}

Assistive Technology provision in Belo Horizonte SUS conforms to the 'medical model' of service delivery, as defined by AAATE, in which the prescription of an AT device is the responsibility of a qualified professional and AT eligible for public provision is usually regulated by a list of products or product specifications, with or without established prices or reimbursement thresholds [1]. Confusion could arise with the definition of the 'medical' model of disability. A 'medical' model of disability implies that people are disabled as a consequence of their own condition, and seeks to either remedy the impairment through medication, rehabilitation and surgery, etc., or through adaptive aids and equipment [28]. While the AAATE classification indicates an organizational model to differentiate existing approaches to AT SDS, the data indicates an outdated approach towards disability. It does not mean that Brazil fits both classifications. On the contrary, the publication of UN CRPD as a federal decree and the VSL investments in the areas of social inclusion, access to education, accessibility and health care give reason to believe that Brazil is moving towards a 'social' model of disability, which sees people as disabled or enabled by the social context in which they function and proposes that changes in the social context or environment can remove or alleviate disability. 


\subsection{User Pathways to access assistive technology}

In Belo Horizonte city, SDS for public AT provision occurs by means of three SUS rehabilitation centres called CReab (an abbreviation for centro de reabilitação). A user's pathway to access the ATs after being referred to the CReabs was outlined during an initial interview with a member of staff coordinating the three CReabs in Belo Horizonte. Visits to each CReab institution with further interviews and participant observations at preparatory stage were then used to confirm this information and to investigate the specific realities of each location.

In their first visit to the service, the users go through a screening process on a firstcome, first-served basis. This screening consists mostly of the users bringing their referral, having their requirements quickly assessed and being scheduled to the necessary services. When referral relates to an ATD, users are scheduled to an assessment specific to their referral, and the procedure varies according to the type of ATD and the centre providing them (see Figure 1 and 2).

The pathway was found to be similar in two centres (see Figure 1), which varied in some aspects from the other centre (see Figure 2). One difference relates to the splints and upper limbs' orthotics offered. In CReabs 1 and 3 this service is restricted to those users taking part in a rehabilitation program at these centres. In CReab 2 there is no such distinction and splints and upper limbs' orthotics services are offered to all users whom staff consider necessary. The main reason claimed by participants to explain such differentiation was that various types of splints and upper limbs' orthotics were not included in the SIA/SUS list by the time this study was conducted. In order to produce them, CReabs staff needed to use a local budget which is different from that associated with the list, shared between other healthcare institutions. Accordingly it is, hence difficult to rely upon in order to accommodate all users in need.

A further relevant difference between service pathways relates to hearing aid and cochlear implant services. All users in need of these services are referred to CReab 2. There, the user will undergo an internal assessment to verify the need for the device and define the service characteristics. The user is then referred to a third-party clinic to receive the treatment and/or devices.

There are two possibilities when a piece of AT that is not offered on the SIA/SUS list is required and claimed by the user by means of referral. The most common seem to be users purchasing the equipment themselves. In this case, the staff are encouraged not to support the user on choosing equipment outside the list, as the user should receive no support from CReab service staff when this happens. Despite this fact, some staff commented that they provide guidance to users whenever they can, despite not being recommended to do so. The other possibility is by pursuing legal means. In this case users are referred to the SMSA where each case is assessed individually and items are purchased directly by SMSA. Most participants mentioned that this process is bureaucratic and time consuming. 


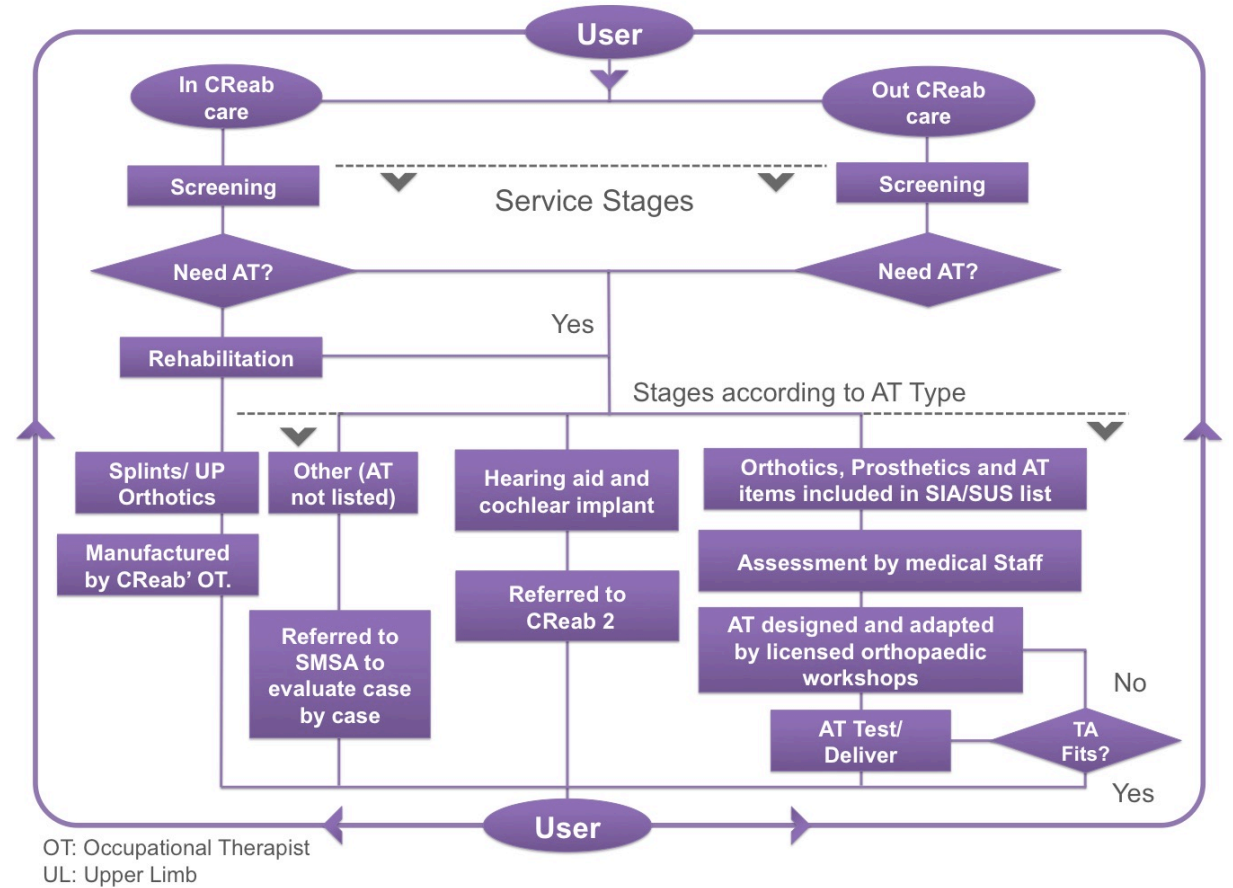

Figure 1. User Pathways to access assistive technology devices in CReabs 1 and 3.

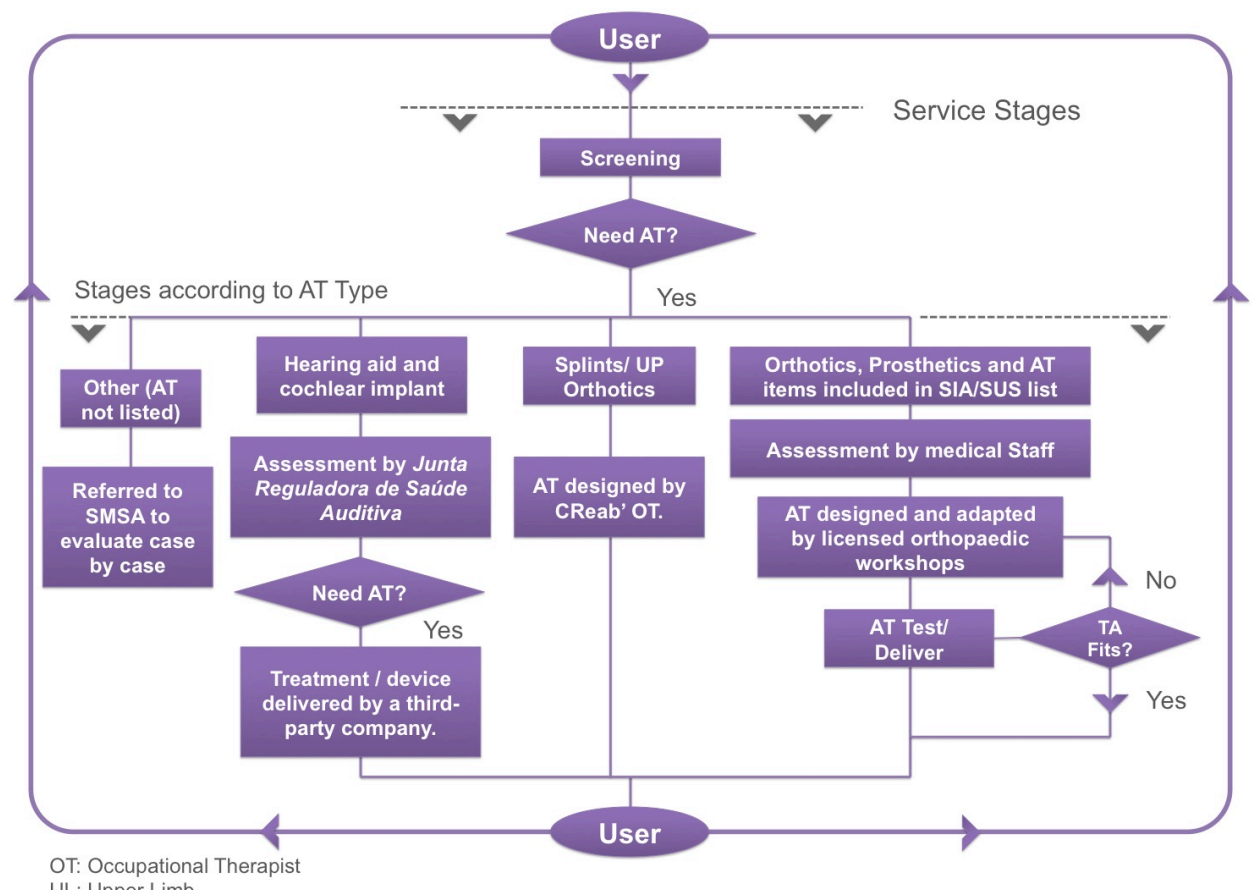

UL: Upper Limb

Figure 2. User Pathways to access assistive technology devices in CReab 2. 


\subsection{Exploring Service Staff Difficulties and Expectations}

During the interviews participants were asked the following question:

- What are the main difficulties faced in providing a quality AT service? (author translation)

It is worth mentioning here that quality service was not previously defined at this point as the question intended to gather the staff impressions regarding their overall difficulties to provide what they consider as a quality services, or in another way, a better service. The main difficulties staff reported encountering (in order of most frequently claimed) were: 1) inflexibility of the list; 2) lack of physical space; 3) access to training; 4) issues with the public-private partnership.

Regarding the inflexibility of the list, it was frequently commented that the list is incomplete and there is often demand for similar models or AT variations from those that are offered. One participant mentioned that these items do not necessarily cost more, but they are not listed or are not according to specifications, so they cannot be provided or contracted.

The lack of physical space is an issue easily recognised as one can see various wheelchairs stocked through corridors of CReabs (see Figure 3). The lack of physical space was said to directly affect a number of issues: the service queue, the contracted services, the implementation of new stages and the user's comfort while at the CReabs. One of participant's comments regarding the expected changes reflects well these concerns:

"...it would need more physical space, because one thing leads to the other. We need more suppliers, however, we need more staff to accompany them... if you see our working conditions it's everything tight, all that (supplied) wheelchairs and patients tight here, it's not ideal. Ideal is to have a better space to host these patients, to have more and good orthopaedic workshops to bring these technologies, to improve the list, because it's a combination of factors." (Interview with staff member at CReab 3, author's translation)

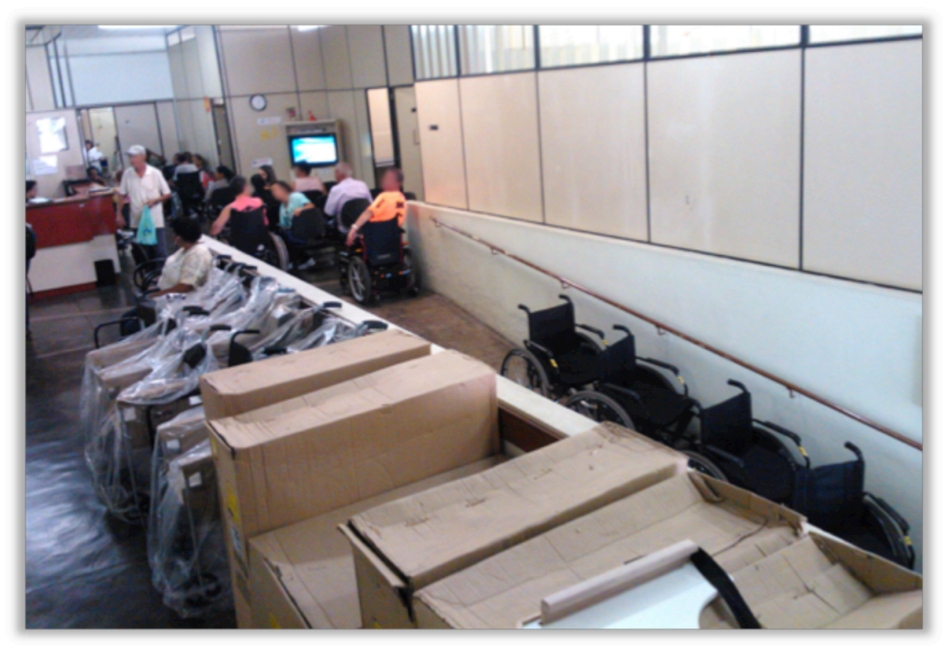

Figure 3. ATDs stocked through the corridors of one CReab 
The main issues with the public-private partnership reported had regard to: lack of AT suppliers at both local and national levels, variation between supplier's service quality, difficulty in guaranteeing the quality of AT delivered and to accommodating CReabs' internal demand and supplier demands.

It was also noted during the observation stages that some devices or device specifications from the list were not being provided at CReabs, such as specific power wheelchair controls. When questioned about this, service administrators and suppliers said that the main reason was the lack of existing suppliers, or lack of suppliers willing to offer the devices at established prices. It was mentioned that the last price update regarding items on the list occurred in 2007.

Participants were also asked about changes they would like to see in the service. The three main categories that emerged from participant's answers (in order of the most frequently claimed) were: 1) to have more knowledge/training support 2) to introduce a user follow-up stage and 3) to improve the physical space within CReabs.

Examples of reported training requirements related to AT prescription, using existing assessment methods and knowing existing technologies. The term 'knowledge supports' refers to the use of standardised assessment and measuring tools, knowledge support from university and consultancy services, access to tools and training, and time available to study at work. To introduce a user follow up stage was also a great concern. One participant commented:

"What is the point of giving expensive devices and not having a follow up? I think we are throwing money away by not accompanying these users...I think the follow-up is the SUS's greatest difficulty in order to function as a whole. The user leaves the service with a prosthetic, use it once and put it inside the wardrobe because it hurts, instead of coming here and saying: I am not going to use that - and then he put it into the wardrobe, as we known it also happen with wheelchairs. So I believe that follow up is a big issue." (Interview with staff member at CReab 1, author's translation)

\subsection{Exploring Service Staff Difficulties to Apply Best Practices}

The main difficulties reported by CReab staff to apply the best practices recommended by AAATE's user influence quality indicators are summarised in Figure 4. These are categorised according to the AT service stages suggested in EASTIN \& AAATE [1]. The Swiss Cheese model for cumulative effects was used subsequently to data collection to organize and present the main findings. A Swiss Cheese model helps identifying cumulative failures in various stages of a process or complex system that can lead to accidents. The holes represent active failures and latent conditions. A bad outcome occurs when the holes in various layers line up to permit a trajectory allowing an accident to occur [29]. In this case, the accident was interpreted as the risk of the AT not fitting the user profile. 


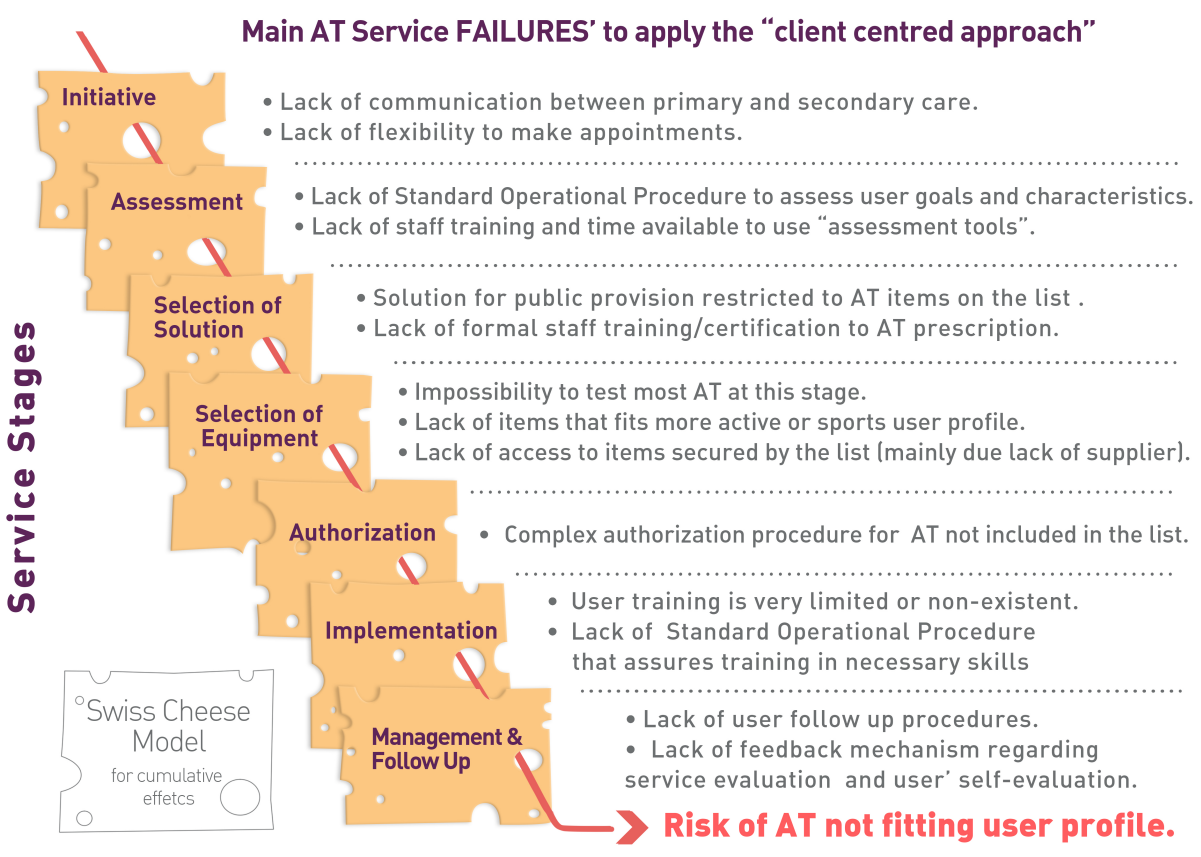

Figure 4. Swiss Cheese model of main AT failures to apply the "client-centred approach" at CReabs

It was found that the service still lacks important stages suggested as best practices, such as: testing the device before taking a decision, providing users with appropriate training with the device, and having feedback mechanisms regarding service evaluation and user self-evaluation.

With regards to the assistive solution provided, concerns were raised regarding both internal and external aspects to CReabs. One internal concern is that the service lacks a mechanism to guarantee and stimulate that a multidisciplinary team assesses users requirements, as suggested by best practice $[1,23]$. Other internal concern relates to the lack of mechanism to assure that user requirements are assessed beyond the ATD(s) item(s) prescribed when they arrive at CReab service, assuring they will benefit for all SIA/SUS items they might require. An external concern about the assistive solution provided is that it should be more integrated with other ATDs and AT services available through other VSL policies, such as accessibility and access to education. These are currently assessed separately and the service lacks effective mechanisms to exchange and integrate staff knowledge towards defining an assistive solution. 


\section{Conclusions}

This study showed that Assistive Technology public services in Belo Horizonte city, Brazil fit the 'medical model' of service delivery defined by AAATE. It is likely that this is also true across Brazil as the public health service functions similarly throughout the country. Nonetheless, this does not mean that Brazil adopts the so-called "medical" model of disability. On the contrary, the ratification of UN CRPD and the Viver Sem Limites programme policies give us reason to believe that Brazil is moving towards a 'social' model of disability.

It was also found that the service still lacks important stages suggested in best practice literature, such as testing the device before taking a decision, providing users with AT training and having feedback mechanisms. From the perspective of service staff, more knowledge support should be provided, a follow up stage should be introduced and rehabilitation centres' physical space should be improved. The SIA/SUS list is considered rigid and the process of requesting AT not offered on the list bureaucratic and time-consuming.

Literature indicates that failure to employ recommended best practices (i.e. those aiming to increase user involvement in matching delivered AT to their needs) expose the process to risk of wrong or ineffective intervention, abandonment of the devices provided and waste of resources.

Further studies aim to design participatory interventions with service stakeholders and provide service recommendations based on main difficulties in applying best practices.

\section{Limitations}

One specific aspect grounded the limitations of this study and the research overall, which is the fact the researcher was conducting the data collection on his own. Hence, the region to be covered and amount of persons to be interviewed had to be restrained and focused. As a consequence of this, the data collection was restricted to the service provided at Belo Horizonte city' secondary care. The service provided at primary care was planned to be included initially and ethical clearance was obtained to do so. However, the pilot study indicated that it would be impractical to include the primary care in the study mostly due time constraints.

Other limitations are with regard to covering the variety of existing quality indicators when assessing the assistive technology services. Again, the time and research size constraints did not enable assessing all aspects of the service. Hence, this study focused on assessing HEART Study's user influence quality indicator. The main reason for selecting this quality indicator rather than any other is because it is the one that pledges that the system should be designed from a user-centred approach. 


\section{Acknowledgments}

We gratefully acknowledge the funding provided by the Brazilian Government programme Science Without Borders. The authors would like to thank Sean Mitchell from Loughborough University for the valuable insights given. In addition, we extend our thanks to the various people from the assistive technology field in Belo Horizonte who generously made time and provided much useful information for the research.

\section{References}

[1] Association for the Advancement Of Assistive Technology In Europe and European Assistive Technology Information Network, Service Delivery Systems For Assistive Technology In Europe [Position paper], 2012

[2] Brasil, Decree $\mathrm{N}^{\circ} 3.298,20$ December 1999.

[3] Brasil, Decree No 5.296, 2 December 2004.

[4] J.C.D. Garcia, and G. Filho, Pesquisa Nacional De Tecnologia Assistiva, [pdf] São Paulo: Instituto de Tecnologia Social, 2012

[5] J. S. Paim, Atenção à Saúde no Brasil, In: M. Saúde. Ed. 2004. Saúde no Brasil - Contribuições para a Agenda de Prioridades de Pesquisa, Brasília: Ministério da Saúde, 2004, 15-40.

[6] D. Varella, O preço da saúde, Folha de São Paulo, 2014.

[7] J. G. Temporão, Para onde vai o SUS? CONASS Seminar, 2013.

[8] L. C. G. Bernardes, I. M. M. L. Maior, C. H. Spezia, \& T. C. C. F. Araujo, Pessoas com deficiência e políticas de saúde no Brasil: reflexões bioéticas, Ciência Saúde Coletiva 14(1) (2008), 31-8.

[9] Secretaria de Direitos Humanos, Convenção sobre os Direitos das Pessoas com Deficiência: Protocolo Facultativo à Convenção sobre os Direitos das Pessoas com Deficiência, Legislative Decree n. 186, in $09^{\text {th }}$ July 2008: Decree n. 6.949 , in $25^{\text {th }}$ August 2009, $4^{\text {th }}$ ed. Brasília.

[10] Secretaria Nacional da Promoção dos Direitos da Pessoa com Deficiência, Cartilha do Plano Viver sem Limite. Brasília, 2013.

[11] Comissão Nacional de Incorporação de Tecnologias no SUS, Procedimento Adaptação Postural Em Cadeiras De Rodas Na Tabela De Órteses, Próteses E Materiais Especiais Do SUS, Brasilia, 2013.

[12] P. Encarnação, L. Azevedo, \& G. J. Gelderblom (Eds.) Assistive Technology: From Research to Practice:AAATE 2013, Vol. 33, IOS Press, 2013.

[13] DGXIII/TIDE, HEART Final Report on Service Delivery, European Comission, 1995, R. Andrich, \& L. Witte (commented version), 2012.

[14] A. M. Cook, and S. Hussey, Assistive technologies: Principles and practice, Elsevier Health Sciences, 2001.

[15] G. J. Gelderblom, L. P. de Witte, M. J. Scherer, \& G. Craddock, Matching Person \& Technology (MPT) assessment process. Technology \& Disability 14(3) (2002): 125-132.

[16] Instituto Brasileiro de Geografia e Estatística, Projeção da população do Brasil e das Unidades da Federação, (2015), Available at: http://www.ibge.gov.br/apps/populacao/projecao/.

[17] Instituto Brasileiro de Geografia e Estatística, Censo Populacional 2010, (2010), Available at: http://7a12.ibge.gov.br/vamos-conhecer-o-brasil/nosso-povo/caracteristicas-da-populacao.

[18] P. T. Lucchese, Eqüidade na gestão descentralizada do SUS: desafios para a redução de desigualdades em saúde. Ciência \& Saúde Coletiva 8(2) (2003), 439-448.

[19] Instituto Brasileiro de Geografia e Estatística, Estimativa da população 2015, [Minas Gerais » Belo Horizonte $\gg$ estimativa da população 2015], 2015, Available at: http://www.cidades.ibge.gov.br/xtras/temas.php?lang=\&codmun=310620\&idtema=130\&search=minasgerais\%7Cbelo-horizonte\%7Cestimativa-da-populacao-2015- .

[20] Instituto Brasileiro de Geografia e Estatística, Censo Demográfico 2000: Características da População e dos Domicílios: Resultados do universe, (2000), Available at: http://www.ibge.gov.br/home/estatistica/populacao/censo2000/

[21] E. A. Baptista, \& J. I.R. Rigotti, Minas Gerais e sua população de deficientes: um estudo a partir dos Censos Demográficos de 2000, Caderno de Geografia 24 (41) (2014), 98-118.

[22] Secretaria Municipal de Saúde de Belo Horizonte, Produção Anual de Órtese/ Prótese/ Meios Auxiliares de Locomoção e Cadeira de Rodas,[Central de APAC], 2012.

[23] Association for the Advancement Of Assistive Technology In Europe-AAATE, A 2003 view on 
T. Maximo and L. Clift / Assessing service delivery systems for assistive technology in Brazil

Technology and Disability [Position paper], 2003.

[24] M. M. K. Oishi, , I. M. Mitchall, and H. M. Machiel Van der Loos (eds.),,Design and Use of Assistive Technology. Social, Technical, Ethical, and Economic Challenges, New York: Springer, 2010.

[25] I. Andrew, J. D. Batavia, and S. H. Guy,Toward the development of consumer-based criteria for the evaluation of assistive devices. Journal of Rehabilitation Research and Development 27(4) (1990).

[26] C.C. Josetti, O arcaico e o moderno na escola brasileira : um enfoque da sociolinguística educacional. Ph.D. Universidade de Brasília, Brasília, 2011.

[27] V. Braun, \& V. Clarke, Using thematic analysis in psychology. Qualitative research in psychology 3(2) (2006), 77-101.

[28] P.J. Clarkson, R.Coleman, S. Keates, and C.Lebbon, (eds.) Inclusive Design: design for the whole population, London: Springer, 2003.

[29] J. Reason, Human error: models and management. BMJ : British Medical Journal 320 (2000), 768-770. 